\title{
Conceptualising and measuring Defensive Marketing Orientation (DMO): some inaugural thoughts on assessing marketing's place in society's doghouse
}

\author{
Authors \\ Dr Tony Woodall \\ Division of Marketing, Retail and Operations \\ Nottingham Business School \\ Nottingham Trent University \\ Nottingham NG1 4BU \\ Dr Stephen Swailes \\ Department of Organisational Behaviour and HRM \\ Hull University Business School \\ Hull HU6 7RX
}

\section{Please send correspondence to:}

Dr Tony Woodall

Division of Marketing, Retail and Operations

Nottingham Business School

Nottingham Trent University

Nottingham

NG1 4BU

Tel: 01158484313

Fax: 01158486175

Email: tony.woodall@ntu.ac.uk 


\title{
Conceptualising and measuring Defensive Marketing Orientation (DMO): some inaugural thoughts on assessing marketing's place in 'society's doghouse'
}

\begin{abstract}
Many commentators suggest that marketing should be at the heart of strategic decision making, yet lament its continued inability to establish a presence at business's top table. Such failure is generally deemed to be the fault of the organization at large, and there is a generally implied presumption that marketers are unfairly marginalized. For marketing to succeed, however, it must be perceived as both credible and contemporary, yet there are small, though substantive, bodies of research implying, 1) that marketing's reputation is still far from ideal and, 2) that practicing marketers prefer traditional means of endeavour that are likely counter-productive in the context of new, customer-focused, manifestos. Analysis of both the marketing and psychology literatures reveals that there is no existing measure that might be used to evaluate attitudes of marketers toward either $\mathrm{MO}$ or post-MO marketing concerns and that, consequently, we never test the commitment of the agent most critical to marketing's strategic aspirations. This paper makes a strong case for the rectification of such deficiency and, via critical reflection on some recent debates concerning marketing measures, suggests an inaugural perspective on how evaluation might be achieved. An agenda for further research is offered, too.
\end{abstract}

\section{Keywords}

Marketer attitudes, defensive marketing, critical marketing, attitude measurement 


\section{Introduction}

At the approach of the new millennium the Journal of Marketing (JoM) published a special edition that focused on the need for marketing to adopt a wider and more relevant organizational role (e.g. Deshpandé, 1999; Rust and Moorman, 1999; Srivastava, Tassaduq and Fahey, 1999). In 2005 similar issues were visited in a series of JoM essays that, again, progressed a view that marketing should move beyond tactical roots and adopt a more complex, strategy-defining role (e.g. Brown, 2005; Sheth and Sisodia, 2005; Webster, 2005). More recently Rust (2006) demanded that marketing should look to occupy a more substantial position within the organization; that it should adopt a more mature and confident approach - coincidently more at ease both with itself and its operational context.

All articles were characterized by a degree of unease, suggesting that - without action - marketing was in danger of being marginalized: of failing to see, and feature in, the bigger picture. Similar bursts of angst have been noticeable, too, in the UK literature. Rudd and Morgan's (2003) editorial to the September special edition of the Journal of Strategic Marketing and, more recently, Mattsson, Ramaseshan and Carson's (2006) call for marketing to 'reclaim corporate strategy', both evidenced marketing's apparent reluctance - or inability - to claim a place at the heart of the organization. In all of these contributions there exists a sense that marketing has failed to overcome its mid-life crisis (e.g. Brown, 1995; Brady and Davis, 1993; Wilson and McDonald, 1994) and - as marketing now concludes its three-score years and ten (Rust, 2006) there is perhaps a fear that a new, and this time potentially terminal, crisis awaits. Unless marketing grasps the strategic nettle it will, apparently, irreversibly fail to assert its potential. 
We take this apparent malaise as a point of departure, and suggest its primary source may be an enemy from within. We hope, too, that our inaugural research will encourage further exploration of the attitudes and proclivities of a familiar, yet barely understood, organizational agent. And in pursuing one particular approach to fathoming the mindset of this particular entity, we also question some empiricist touchstones and offer, also, a view on recent debates concerning the development of marketing-related measures.

\section{Marketing's role}

Given the arguments above concerning marketing's failure to capitalise upon seventy years of sustained development, we perhaps first need to ask one very pertinent question: who, or what, is this apparently inert and baleful phenomenon called 'marketing'? Who, or what, is it that is failing to take the lead? The meaning of the word 'marketing' is, of course, extraordinarily diffuse, and can represent a wide range of ideas (see Figure 1., below):

Figure 1: Marketing's many meanings

1. A department, or organizational function/entity, populated by those we call 'marketers'.

2. An endeavour; something an organization engages in to facilitate its market aspirations.

3. A set of practices/techniques, often associated with the $4 \mathrm{P}$ 'marketing $\mathrm{mix}^{\prime}$, plus a range of devices that collectively approximate as marketing planning, market research, segmentation, targeting and positioning.

4. An academic discipline, sustained by a substantive body of written knowledge generated and maintained by those who research and teach 'marketing'.

5. A concept, one that differentiates 'marketing' from 'selling', and that focuses on 'pull' from the customer, rather than 'push' from the organization.

6. A manifestation, primarily perceived by non- marketers, as method (advertising, direct mail, etc.) or philosophy (variously interpreted as persuasion, exploitation, or information).

7. A discourse, concerned primarily with the notions of materialism, consumerism and conspicuous display. 
Perhaps most of the literary references to marketing are implicit and demand an intuitive response; one that attaches common meaning embracing much of the diversity detailed in Figure 1, above. Closer analysis, though, shows this is not always the case. Holbrook and Hulbert's (2002) elegy on the death of marketing, for example, quite clearly pertains to item 3; Brown's (1995) take on marketing's mid-life crisis is essentially about item 5; Woodall (2004) talks principally of item 2, whilst Abela (2006) and Wang and Wallendorf (2006) are concerned with the social implications of marketing and bring to mind items 6 and/or 7. As with many other contributions, however, Mattson, Rameseshan and Carson's (2006) notion of marketing as Grand Strategy demands a combined perspective - with philosophy, function and community of practice all at one, collectively in tune with a common sense of endeavour.

For marketing (as a collective entity) to a assert itself as a credible, positive and convincing force, however, it must first sharpen-up its brand image, and ensure that all aspects serve to support its aspirational base; for beyond its immediate adherents, marketing is seen in less than wholesome terms. Sheth and Sisodia (2005), for example, report on recent research suggesting $62 \%$ of consumers have a negative attitude toward marketing, and that only $10 \%$ are prepared to articulate positively on its merits. In respect of marketing's relationship with the market there exists, according to Singhapakdi et al (1999) an 'ethics gap'; a gap that represents the difference between behaviour that consumers think is acceptable and that which marketers appear to accept as appropriate. Babin, Boles and Robin (2001, p. 349), for example, speak of marketing environments as places "... where implicit trusts are confronted and are either kept or breached" - and where, often, the consumer views marketing with cynicism (Dobscha, 1998; Moorman, 1998), ambivalence (O’Donohoe, 2001) or scepticism (Tan, 2004). 
The problem is, of course, that marketing is more frequently associated with indulgence and greed than with customer satisfaction, its purported raison d'etre; and is frequently seen to be feeding, and feeding off, associated and essentially human weaknesses. Marketing, objectified largely in terms of item 7 above, is perceived as a perpetrator, rather than facilitator, and it is perhaps not surprising, therefore, that “... there is a lack of respect within the corporation and a lack of trust by consumers. Taken together, these two major deficiencies have placed marketing in society's doghouse as a shallow, wasteful, and polluting influence." (Sheth and Sisodia, 2005, p. 160). Despite evidence of the marketer's apparent value to the organisation (e.g. Weinzimmer, et al, 2003) what chance, then, a place at the heart of the organization - with an opportunity to seize and influence the strategic imperative?

\section{Marketing and the marketer}

But who, or what, is at fault? Certainly perceived as a concept, a profession, and an academic discipline marketing has the dual interests of both customer and firm at heart, and its role as a unifier of corporate interest and activity is beyond doubt. But to what extent do marketing practitioners agree with such virtuous aims? To what extent do they believe in marketing as a means of serving, as opposed to duping, the customer? Would they agree with Arizona State's Stephen Brown who suggests marketing should be 'strategic management, operations, supply chain management, human resources and finance'? (Brown, S. W., 2005). Or are they, as Woodall (2004) hypothesises, still essentially 'hard-wired to the hard-sell'? Palmer and Ponsonby (2002) suggested that despite a plethora of new marketing manifestos, marketing on the ground is pretty much still the way it has always been, whilst much of the recent output from Ulster's Stephen Brown (from Brown, S. 1999, through to Brown, S. 2005) essentially reasserts rightly or wrongly - stereotypical marketing characteristics and behaviours. 
A few articles have sought to evaluate the way that practitioners either a) perceive their role, or b) understand the expectations placed upon them by either society or the organization. These include Clark (2000), who investigated how marketing managers judged the performance of strategies and tactics they employed, and Ardley (2005) who recently reported upon perceptions of marketing manager decision making. Rudd and Morgan (2003, p. 162) described work by the PA Consulting group that investigated marketers' perspectives on their own, and colleagues', role within the organization, whilst Nicole Coviello and colleagues have reported extensively on marketers' views on marketing practice in a range of international contexts (e.g. Coviello, et al, 2002); Brady and Palmer (2004), too, have undertaken similar work in Ireland.

Most studies reported similar findings; that marketers are generally resistant to change, both in terms of practice and their role within the firm. According to Rudd and Morgan (2003, p. 162), marketers are "comfortable on their own turf-doing what marketers have always done, within their functional boundary." These isolated examples provide some insight into the way that practitioners feel and behave, yet the marketing academy often appears to assume, or perhaps to hope, that its aspirations are always aligned with those of the marketer at large.

\section{Exploring marketer attitudes}

Clearly, there is more than a suggestion that the ideas and attitudes of practicing marketers are somewhat different to those that the academy would prefer them to be. Yet we know little about what marketers actually think about customers; or how marketers might react to the suggestion that they are 'just' the full-time component of a much wider marketing constituency; or how they feel about interfunctional co-ordination and the organization-wide dissemination of the marketing 
intelligence they have collected. In short, we have no real idea of the extent to which marketers, themselves, are market oriented.

The marketing canon tells us that the marketing project, primarily operationalised through the achievement of market orientation (MO), can be of substantial benefit to organizations (Kirca, Jayachandran and Bearden, 2005; Ellis, 2006). The literature, though, from Narver and Slater, and Kohli and Jaworski (1990 both - the start, according to Foley and Fahy, 2004, of 'true' market orientation debate) onwards, focuses almost entirely upon MO as a phenomenon conceptualized from the aggregate, or organizational, perspective. This literature is substantial; but investigation of a random, recent, sample covering a wide range of contexts (Bathgate, et al, 2006; Chatzipanagiotou, Vassilikopoulou and Siomkos (2008); Dwairi, Bhuian and Jurkus, 2007; Kolar, 2006; Macedo and Pinho, 2006) demonstrates a continuing reliance on founding MKTOR (Narver and Slater, 1990) and MARKOR (Kholi, Jaworski and Kumar, 1993) models of measurement, both of which focus on the firm, as a whole.

The bulk of the MO literature, therefore, seeks to model the extent to which the organization accepts, endorses and operationalises the marketing concept. Although never stated, this approach presumes that marketers are invariably 'on message' and that failure to adopt/adapt is most likely a result of 'dysfunctional conflict' (Maltz and Kholi, 2000) instigated by those within, for example, finance, $R \& D$ and operations. Interestingly, as far back as 1984 , it was noted by Mitchell and Agenmonmen (p. 63) that "attitudes of marketing academicians and practitioners are key agents in the adoption and implementation of the marketing concept philosophy" yet this assumption has neither been challenged nor tested to any substantial degree (though see Dailey and Kim, 2001, and Best, 2000, for perspectives on 'Marketing IQ'). 


\section{Beyond market orientation}

Perhaps, though, the literature concerning similar, but different, orientations might reveal further insight into how marketers perceive their role and purpose. One potential candidate is Customer Orientation (CO), considered by Deshpandé, Farley and Webster (1993), to be either explicitly or implicitly 'synonymous' with market orientation. The literature concerning $\mathrm{CO}$ is more balanced than that relating to $\mathrm{MO}$ and embraces both aggregate and individual level perspectives.

For the former, work by Deshpandé, Farley and Webster (1993) is the point of departure. Their particular version of $\mathrm{CO}$ was contained within a multi-scale instrument designed also to measure innovativeness and corporate culture, and a number of other researchers, since, have taken $\mathrm{CO}$ as being similarly integral to a market oriented approach to doing business. Egan and Shipley (1995), Luo and Seyedian (2004), and Rindfleisch and Moorman (2003) all contain scales that either use, or are influenced by, statements, characteristics or criteria that effectively measure organisational 'orientation to the market' (Halliday, 2002) - but as seen from outside the firm. In this respect CO is frequently represented as a 'mirror' of MO (Andreasson, 1994) and, clearly, takes no account of the views of marketers. Individual perspectives on $\mathrm{CO}$ are primarily associated with the work of Saxe and Weitz (1982). Since its inception their SOCO scale has been the subject of substantial psychometric improvement (Michaels and Day, 1985; Thomas, Soutar and Ryan, 2001) and also domain extension (e.g. Boles, et al, 2001; Tadepalli, 1995). Other researchers have undertaken empirical work that uses just (Hoffman and Kelly, 1994) or mostly (Brady and Cronin, 2001) the 'positive'/'customer orientation' half of the battery, whilst others (Donavan, Brown and Mowen, 2004; Hajjat, 2002) have developed new scales that use SOCO as a frame of reference. 
Generally, however, such measures are applied either to service workers (Brown, et al, 2002; Liu and Chen, 2006) or salespeople (e.g. Franke and Park, 2005; Harris, Mowen and Brown, 2005) and, occasionally, scales have been used in conjunction with MO-influenced metrics to help determine the influence of aggregate organizational orientations upon those of individuals (Kelley, 1992; Siguaw, Brown and Widing, 1994). Although individuals assessed can, broadly, be categorized as marketers, these are largely customer-facing personnel (or 'part-time' marketers; Gummeson, 1991) and not those who market strategically, or 'full-time'.

This is similarly the case with the only other frequently evaluated, synonymous tendency, Service Orientation (SO). Also more clearly associated with the part-time rather than full-time marketer individual-level SO is, anyhow, considered to be a behaviour rather than a personal trait or attitude (Donavan, Brown, Mowen, 2004). Hogan, Hogan and Bush (1984) consider SO to be a 'behavioural syndrome' equated to, or associated with, particular personality characteristics. Other SO scales (e.g. Cran, 1994; Frei and McDaniel, 1998; Carraher, et al, 1998) are similarly based upon the assumption that specific individual tendencies can be associated with 'appropriate' service work/worker behaviour. Exceptionally, Susskind, Kaemar and Borchgrevink (2003) assess SO as an attitude but, as with other associated studies, the 'marketers' concerned are not decision-makers.

Aggregate level measures are generally used to determine whether employees and/or customers believe a specific organization has adopted appropriate service-related policies. The SERV*OR scale developed by Lytle, Hom and Mokwa, 1998, has been used in various contexts (see also Lyn, Lytle and Bobek, 2000; Lytle and Timmerman, 2006) and by Saura, et al, (2005), in 
association with other scales, including one for CO. Similar scales (e.g. Homberg, Hoyer and Fassnacht, 2002; Schneider, White and Paul, 1998; Wright, Pearce and Busbin, 1997) have used SO construct derivations as a means of gaining insights into aspects of business strategy, culture and/or climate - but always as it applies to the organization as a whole; and never to marketing as a specific community of practice.

There are myriad other analagous orientations within the literature (consumer orientation Sanchez and Fuentes, 2002; customer service orientation - Wright, Pearce and Busbin, 1997; public relations orientation - Black and Härtel, 2002; quality orientation - Mohr-Jackson, 1998; societal orientation - Liao, Foreman and Sargeant, 2001; service firm marketing-culture Webster, 1993) but none attempt to capture the attitudes of the practicing 'full-time' marketer.

\section{Introducing Defensive Marketing Orientation (DMO)}

The key objective of this paper is to redress the relative lack of research into 'full-time' marketer attitudes and to encourage some further research into a little understood/explored domain. The medium chosen for undertaking this work is a construct termed 'defensive marketing orientation' (DMO), the genesis of which can be found in Woodall (2004). Here it was argued that marketing activity, in its broadest sense (see item 2 in Figure 1), can be conceptualized as a binary phenomenon having both a 'defensive' and an 'offensive' aspect.

Although already employed within the marketing literature, the terms offensive and defensive marketing are used differently here. They are selected primarily for their inherent syntaxical ambiguity, a choice that draws upon Fromm's (1949) notion that all orientations have contrasting, and potentially contrary, elements. Thus, although often applied in the context of 
customer acquisition (Rust, Zahorik and Keiningham, 1996) the term 'offensive' can more literally be seen to have two meanings; one synonymous with the words distasteful or unpleasant - and thus highly relevant to Sheth and Sisodia's (2005) description of marketing as a 'polluting' influence - and the other suggestive of competitive and/or proactive behaviour, as exemplified by Hugh Davidson's work (Davidson, 1972; Davidson, 1997; Keegan, Davidson and Brill, 2005). Thus the term 'offensive' serves to conjoin both aspirational and contestable elements inherent to one particular style of marketing - one normally associated with the 'full-time' marketer.

The term 'defensive' is conventionally applied within the context of customer retention (Rust, Zahorik and Keiningham, 1996; Fornell and Wernerfelt, 1987) but also, more literally, implies the building a tactical fortress against the acquisitive mores of the competition (Hauser and Shugan, 1983; Kumar and Sudharshan, 1988). Again, though, a literal interpretation of the term 'defensive' might imply a certain diffidence, or lack of marketing-like 'chutzpah', that the more aggressive full-time marketer might wish to avoid. Essentially, defensive marketing is the domain of the 'part-time' marketer, and suggests the notion of quietly, but effectively, marketing through the medium of product and/or service performance, with the overall intention of both retaining and winning customers.

Thus, 'offensive marketing' preferences those satisfaction-related practices that relate to identifying goods and services the customer might want, and of facilitating/promoting their availability; whilst 'defensive marketing' is concerned with satisfaction-related practices employed in the broad-scale delivery of those goods and services. This latter, coincidentally, is conceptualised also as concerning organizational behaviours/attitudes related, for example, to 
governance or the environment, which - though not necessarily directed by the marketing department - can also have a substantial impact on consumer behaviour.

Figure 2 Definitions of Offensive and Defensive marketing

\section{Operational definitions:}

a 'offensive' marketing: Any activity or effect that serves to move the customer closer to, or further away, from purchase or repurchase, and which stems from purposeful endeavour primarily related to product promotion, pricing, placement and targeting, and the determination of product attributes.

a 'defensive' marketing: Any activity or effect that serves to move the customer closer to, or further away, from purchase or repurchase, and which stems from product realisation, product consumption, or the customer's perception of organisational behaviour.

\section{Aesthetic definitions:}

口 'offensive' marketing: Marketing with disdain; marketing for marketing's sake; marketing in an essentially exploitative and cynical manner.

a 'defensive' marketing: Marketing with humility; marketing with an overriding sense of responsibility for society; marketing with probity

Note 1 - 'Product' is a generic term that represents both goods and services and any combination thereof.

Note 2 - For not-for-profit/social 'products', either commitment, engagement, or funding should be considered equivalent to the term 'purchase'.

Defensive marketing, therefore, relates more to performance, whereas offensive marketing focuses on persuasion. This might also be conceptualized as promise-keeping versus promise making (see, also, Grönroos, 2006); and, as evidenced in Figure 2, above, each might be interpreted as having both operational and aesthetic aspects - with operational definitions providing an objective perspective on practice-based issues, but aesthetic definitions profiling the more negative interpretations of both categories, couched in terms that proponents of each might use to characterise the weaknesses of the other. Clearly, these latter can be seen to apply over a 
continuum, though, such that both 'disdain' (an offensive characteristic) and 'probity' (a defensive characteristic) could be either non-existent or absolute.

Given that marketing is a constantly evolving phenomenon, and that recent emphases on marketing ethics (Brinkman, 2002; Carrigan, Marinova and Smizgin, 2005; Nairn and Berthon, 2003); service-dominant logic (Lusch and Vargo, 2006; Grönroos, 2007; Vargo and Lusch, 2004); new demands for organizational responsiveness (Holbrook and Hulbert, 2002; Zeithaml, Parasuraman and Malhotra, 2002); 'meridian' marketing (Carù and Cova, 2003; Cova, 2005); trust (Ball, 2004; Deepak, Singh and Sebal, 2002; Winch and Joyce, 2005) and the value-defining potential of front-line staff (Berry, 1999; De Chernatony, Drury and Segal-Horn, 2004) - all, essentially, defensive phenomena - it seemed appropriate to attempt to test how those who might normally be construed as being vocationally aligned to 'offensive' activity (the 'full-time' marketer) might view this developing domain. And given that other analogous orientations have been conceptualized and evaluated primarily through attitude measures, we suggest that the development of a Defensive Marketing Orientation (DMO) instrument will provide a useful addition to the marketing researcher's armoury.

\section{Methodological discussion}

Most authors advising on structural approaches to attitude/orientation measurement (e.g. Churchill, 1979; DeVellis, 2003; Hinkin, 1998; Oppenheim, 1992) recommend a linear, twophase scale development process. Phase one consists of mapping the conceptual domain, generation of a representative item pool, purification of the item pool to establish content validity, item scaling, and then initial questionnaire administration (followed by analysis of outcomes) focused coincidentally on construct validity, scale reliability and scale parsimony. A 
second phase, concerned mainly with other aspects of validity (criterion, convergent, discriminant) represents the next rational step for the building of robust scales. Key characteristics of this approach are the use of factoring techniques designed to help achieve both 'simple' structure (minimal cross loading) and high levels of inter-item reliability - usually characterized by Cronbach's Alpha in excess of 0.7 (Peterson, 1994). Such instruments are based upon the principle of unidimensionality and indicators are considered to be reflective of the primary construct.

Others, though (for an overview, see Diamantopoulos, Riefler and Roth, 2008) have acknowledged that measurement can also be achieved via the development of an index, an instrument characterized by a formative, rather than a reflective structure. A number of recent contributions to the literature have bought about the rehabilitation of the index, and two particular papers have proved especially influential; the first (Diamantopoulos and Winklhofer, 2001) focusing on index development and validation via a recommended 'MIMIC' methodology, and the second (Jarvis, McKenzie and Podsakoff, 2003) providing clarification on how reflective and formative structures differ. This literature has caused researchers to re-evaluate their approach to the measurement of key marketing metrics, and consideration as to whether a construct should be either scale or index has now begun to assume axiomatic status, with the latter now gaining substantially in credibility (e.g. Diamantopoulos and Siguaw, 2006; Coltman, 2008).

There has, however, been little written about which of the two approaches might be best, or preferred, for a given application. A number of recent papers have sought to establish that structures that have previously only been evaluated via scales should, in reality, be considered to be either fully, or partly, formative constructs (e.g. consumer value, Lin, Sher and Shih, 2005; 
corporate reputation, Helm, 2005; service value, Ruiz, et al, 2008; brand trust, Fuan, et al, 2008). That is, they have sought to suggest that particular theory is (or isn't) formative (or reflective) and, undoubtedly, this re-evaluation of extant knowledge will continue apace.

Diamantopoulos and Winklhofer (2001), and Diamantopoulos and Siguaw (2006), suggest decisions must be made at the very outset regarding which of the two types of measuring instrument is to be pursued. If, on the one hand, low collinearity is preferred, then items must from the beginning - be entirely dissimilar, whilst, on the other hand, high inter-item reliability is only likely to be achieved if similarity is built in. In both cases - for indexes and scales, respectively - however, this can lead to the imposition of potentially constraining preliminary assumptions, with measures becoming self-fulfilling prophecies reinforced, inevitably, through the methods followed; either (usually confirmatory) factoring for scales or, perhaps, the MIMIC model for indexes.

\section{Opportunistic statistics?}

In this paper, though, rather than attempting either to build a scale or construct an index, we have sought to develop a measure based on ideas that represent (rather than reflect or form) a particular construct - and to allow, rather than oblige, a construct to emerge. We note that in recent years applications of factor analysis (for developing marketing measures) have been

primarily employed for confirming, rather than developing, theory - with highest possible Alphas a presumed imperative. In this paper, though, we recognize, a) that the purpose of factor analysis is, effectively, to identify dormant variables that are found via the statistical coalescence of numbers that represent the reactions of responding subjects who are faced with a range of suggested dilemmas and, b) that the possibility of responding subjects reacting in a way that is 
contrary to researchers' expectations should not be considered either unexpected or problematic. Factor analysis can offer a fascinating insight into the way that research subjects think about, and connect, the dilemmas that confront them; and in the same way that the analysis of qualitative data is often most effectively achieved through the search for in vivo, as well as a priori, codes, a similarly interpretive/inductive approach is equally appropriate for 'making sense' of quantitative data. As a consequence, we have taken exploratory principal components factor analysis as our preferred method of analysis.

\section{Mapping the conceptual domain}

Churchill (1979, p. 67) encourages researchers to conduct a "thorough review of literature in which the variable is used" to ensure that conceptual domains are specified through the synthesis of what is already known. The defensive marketing construct used in this paper, however, represents a personalized perspective on the nature of marketing and, consequently, has no clear

provenance. The authors' view does take account of extant perspectives, but combines these with other performance/persuasion-related elements explored in Woodall (2004). Domain content, therefore, is considered to be neither entirely 'out there' (Rorty, 1989), nor fixed within a coherent linguistic realm (Teas and Palan, 1997). Rather, it is an internalized construct derived from a revised perspective on the semantic domain (Pole and Lampard, 2002) and from the researchers' own socially constructed view (Palmer and Ponsonby, 2002) on what marketing should, or could, be. This phenomenon has a prima facie association with the orientations considered earlier in this paper, but any verifiable relationship is neither claimed nor sought.

Novack, the father of 'concept mapping', suggests that "Meaningful learning involves the assimilation of new concepts and propositions into existing cognitive structures." (Plotnick, 
1997) and, essentially, the authors' attempt to re-fix the notions of defensive/offensive marketing substantially aligns with this view. Recommended techniques for developing new ideas are manifold, and - in addition to forensically analyzing the literature - introspective practices such as mindmapping (Wycoff, 1991) and individual brainstorming (Camacho and Paulus, 1995) have been shown to be effective. Using relevant techniques, therefore, it was provisionally determined that an individual marketer's defensive orientation could be evaluated by determining his/her attitude in respect of ....
a) ... the importance of both goods and service quality (Quality);
b) ... the value/role of 'part-time' marketers (Part-time)
c) $\ldots$ the role of corporate reputation (Reputation)
d) ... approaches to the practice of marketing (Marketing)
e) ... customer centricity (Customers)
f) ... internal operational/support functions (Support)
g) $\ldots$ the role of service, generally, as a marketing imperative (Service)

These were consequently hypothesized as key variables underpinning a personally revised perspective on defensive marketing. These were considered to be neither formative nor reflective of the overall construct, a view based upon the assumption that there is a circular and mutuallyreinforcing relationship between marketing and the business/social environment it inhabits.

Following Oppenheim's (1992) suggestion that an initial item pool of 'several dozen' attitude statements should be generated, 104 items, both negatively and positively worded were developed. Some of these were influenced by statements contained within instruments discussed 
earlier, and we especially acknowledge Black and Härtel, 2002; Dailey and Kim, 2001;

Deshpande, Farley and Webster, 1993; Hajjat, 2002; Lytle, Hom and Mokwa, 1998; Narver and

Slater, 1990; Sanzo, et al, 2003; Susskind, Kaemar and Borchgrevink, 2003, and Webster, 1993. Other key influences included outcomes of the authors' prior, qualitative, research within the marketer community.

Following item editing - a process used to filter out redundant, excessively duplicated or poorly worded items - 39 items and one dimension (Service) were discarded; and although symmetry of positively and negatively worded items had not been an initial objective, the edit did result in a relatively evenly balanced selection, both across the item pool and within dimensions.

\section{Establishing content adequacy}

Schriesheim, et al (1993) suggest there is no ideal mechanism for determining content adequacy, but expert evaluation is commonly used in the context of marketing-related measures (e.g. Donavan, Brown and Mowen, 2004; Lado, Mahdeau-Olivares, and Rivera, 1998; Sanzo, et al, 2003). For the DMO study this was facilitated by providing author-generated descriptions of both the construct as a whole, and of contributing dimensions. An expert panel was asked to review all surviving items in the context of the given descriptions, and to provide, 1) a score on a 1-5 Likert scale identifying the extent to which dimensions represented the conceptual domain, and 2) a view as to item-to-dimension fit. Decision rules were that any dimension with a mean score of four or more, and all items attached to a specific dimension by a majority of reviewers, should be retained. 


\section{Evaluating construct validity}

The surviving 49 items were then randomly organized as a questionnaire, with a five-point Likert scale universally applied. Foster (1998) advises that for exploratory research a minimum item-toresponse (or variables-to-subjects) factor of two, and a minimum absolute response number of 100, defines a suitable sample size. Kline (1998) similarly provides support for a 1:2 ratio, but suggests, too, a dimension-to-subject ratio of 1:20. Given both the nature of the item pool (49 items; six dimensions) and that the research was exploratory, a sample size of approximately 120 was considered to be adequate. Programme leaders at 19 Chartered Institute of Marketing (CIM) accredited examination centres were approached to submit questionnaires to programme delegates and, ultimately, submissions from 109 practising marketers were accumulated.

Following an intermediate 'cleansing' stage, where the item pool was reduced to 41 by rejecting items providing little or no discriminatory value, exploratory factor analysis was applied, but with no pre-determined notion of how many factors should emerge. Neiderman (1999), quoting Spector, reveals that a researcher might "rotate several different number of factors and rely on the meaningfulness of the interpretation to decide on the number of factors". Initial evaluation of results was based upon suggestions that factor loading should ideally be above 0.4 (Hinkin, 1998); that cross-loadings should ideally be less than half the principal loading (Hinkin, 1995); and that selected loadings be positive.

Analysis failed to support the original six dimension structure, but through application of the above criteria (adjusted subsequently to also acknowledge loading 'gaps' between opposing components 2 and 3 for items 2c. and 2d.) an encouraging three factor, 16-item, solution emerged (see Table 1). 
Table 1: The Defensive Marketing Orientation (DMO) construct and results

\begin{tabular}{|c|c|c|c|c|c|}
\hline \multirow[b]{2}{*}{ Factor label/items } & \multicolumn{3}{|c|}{ Factor Loadings } & \multicolumn{2}{|c|}{ Descriptives } \\
\hline & $\begin{array}{c}\text { Factor } \\
1\end{array}$ & $\begin{array}{l}\text { Factor } \\
2\end{array}$ & $\begin{array}{c}\text { Factor } \\
3\end{array}$ & Mean & SD \\
\hline 1. Marketing Acknowledgement (Component 1) & & & & 3.48 & 1.11 \\
\hline $\begin{array}{l}\text { a. The training of front-line employees should be an item on the Marketing } \\
\text { Department's budget. }\end{array}$ & 0.53 & & & 3.31 & 1.18 \\
\hline $\begin{array}{l}\text { b. The values of a company/brand are represented primarily through the } \\
\text { actions of its front-line employees. }\end{array}$ & 0.67 & & 0.13 & 3.72 & 1.01 \\
\hline $\begin{array}{l}\text { c. Front-line employees know more about what the customer wants than } \\
\text { do members of the Marketing Department. }\end{array}$ & 0.53 & & & 3.17 & 1.04 \\
\hline d. Front-line employees are full-time members of the Marketing team & 0.56 & 0.10 & 0.13 & 3.75 & 1.08 \\
\hline 2. Marketing Expedience (Component 2) & & & & 3.62 & 0.98 \\
\hline a. When it comes to winning customers the end always justifies the means & & 0.51 & & 3.47 & 0.92 \\
\hline $\begin{array}{l}\text { b. Quality of goods and services is fine provided it doesn't get in the way } \\
\text { of a good idea }\end{array}$ & 0.18 & 0.58 & & 3.63 & 0.90 \\
\hline $\begin{array}{l}\text { c. Corporate social responsibility is fine if it can be shown to improve the } \\
\text { bottom-line but a waste of time if it can't. }\end{array}$ & 0.11 & 0.32 & -0.16 & 3.83 & 0.86 \\
\hline d. Reputation helps, but advertising is the key to increased sales. & 0.28 & 0.37 & -0.14 & 3.41 & 1.00 \\
\hline $\begin{array}{l}\text { e. As we know more about what is possible than the customer, it is our job } \\
\text { to tell customers what they want. }\end{array}$ & -0.20 & 0.62 & --0.17 & 3.48 & 1.00 \\
\hline $\begin{array}{l}\text { f. Marketing is a clearly defined discipline that is distinct from any other in } \\
\text { the organisation. }\end{array}$ & & 0.51 & 0.11 & 3.87 & 1.08 \\
\hline 3. Marketing Idealism (Component 3) & & & & 3.47 & 1.07 \\
\hline a. Marketing practice must be ethically and morally beyond question. & & & 0.69 & 3.90 & 0.88 \\
\hline $\begin{array}{l}\text { b. Marketers should always tell customers the truth, the whole truth, and } \\
\text { nothing but the truth }\end{array}$ & & -0.18 & 0.65 & 3.58 & 1.07 \\
\hline c. Providing better service is a greater priority than providing more service & & 0.19 & 0.41 & 3.97 & 0.97 \\
\hline $\begin{array}{l}\text { d. Before any new product is introduced Marketing should always ensure } \\
\text { that Operations are happy to produce/deliver it }\end{array}$ & & & 0.40 & 3.84 & 1.12 \\
\hline $\begin{array}{l}\text { e. As a marketer, I should always sacrifice short-term advantage for long- } \\
\text { term benefits }\end{array}$ & & -.033 & 0.58 & 2.99 & 0.97 \\
\hline $\begin{array}{l}\text { f. The customers' interests should always come first, ahead of } \\
\text { management's. }\end{array}$ & 0.15 & 0.12 & 0.40 & 3.34 & 1.07 \\
\hline \multicolumn{4}{|c|}{ Aggregate score, Defensive Marketing Orientation } & 3.58 & 1.18 \\
\hline
\end{tabular}

Factor 1 has been named 'Acknowledgement' (see Table 1.) and measures the extent to which marketers are prepared to cede marketing responsibility to those working outside the marketing department (see definition 1, Figure 1). It gauges indirectly, also, the degree to which the marketer believes marketing to be a company-wide endeavour (see definitions 2. and 5.). All items are positively oriented and all emanate from the pre-considered dimension 'Part-time'. A comparison of factor characteristics to Table 1 of Jarvis, MacKenzie and Podsakoff, 2003 (p. 
203: 'Decision rules for determining whether a construct is formative or reflective') and a Cronbach's Alpha of 0.62 suggest a 'reflective' structure mode. Clearly, inter-item correlation is less than desired, but is slightly better than the $0.5 / 0.6$ suggested by Churchill as appropriate for 'early-stage' research (Peterson, 1994). Had a 'scale' have been a pre-ordained outcome, a more analogical character would have been built into relevant items.

Factor 1 has been named 'Expedience'. Items are all negatively oriented but do not emanate from one, individual, pre-considered dimension. They are, though, all associated via disdain for the prejudicial, long-term, repercussions of pragmatic/expedient marketing behaviours. Collectively, the items in, and orientation of, this factor are redolent of a cavalier approach to business that marketers might adopt; and this, consequently, fits well with an aesthetic notion of offensive marketing (see Figure 2, earlier). Cronbach's alpha is just 0.43, but low inter-item collinearity (a maximum Variance Inflation Factor - VIF - reading of well below 10, a virtue for an index - Diamantopoulos and Winklhofer, 2001) conjoin with other characteristics to suggest a formative structure (again, see Table 1, Jarvis, MacKenzie and Podsakoff, 2003, p. 203). Items are variously derived from 'reputation', 'quality', 'marketing' and 'customers' dimensions.

Component 3 has similar formative characteristics to dimension 2 (plus low Alpha, 0.38, and VIF below 10) and also comprises items derived from a range of pre-considered dimensions - this time 'marketing', 'quality' and 'support'. All items are positively oriented and attributionally are the opposite of factor 1. This factor has been named 'Idealism', and suggests a way of thinking that aligns well with an aesthetic characterisation of defensive marketing (see Figure 2). Items in this particular battery all imply an aspirational approach to doing business; one, though, that might be considered, in extremis, to be overly cautious/constraining. 


\section{Discussion and results}

Structurally, the instrument has substantial intuitive appeal. Clearly, it contains one factor (Idealism), that strongly represents the authors' underlying sense of what it means to market 'defensively'. And, also, the antithesis of this - offensive marketing - is clearly embodied in the Expedience factor. In this respect the instrument is not dissimilar to Saxe and Weitz's (1982) SOCO measure, where both customer- and sales-orientation scales are used to measure contrasting aspects of a perceived phenomenon. In addition, though, for DMO there is a third measure, one that addresses marketers' beliefs about those at the heart of defensive marketing part-time marketers. What has emerged, therefore, is a measure that integrates/evaluates the relative weights of contrasting aesthetic marketer perspectives, whilst, coincidentally, considering the marketers attitude' in respect of perhaps the most important operational component of defensive marketing; and all within a relatively, parsimonious 16 item construct. Scoring direction is such that higher values imply a defensive orientation; lower values an offensive orientation.

Collectively, the instrument straddles Type II and Type IV factor specifications (Jarvis, MacKenzie and Podsakoff, 2003) with a formative second-order, and reflective/formative firstorder structure. The authors can think of no reason why such a structure should not exist, and the methodology adopted allows such a possibility to occur. It is, though, understood that some might judge this combined scale/index interpretation " $a$ handy excuse for low internal consistency" (Bollen and Lennox, in Diamantopoulos and Winklhofer, 2001, p.274; Diamantopoulos and Siguaw, 2006, p274) - but any such claim assumes high internal consistency 
as an original aim, and this was not the case. It is clear, though, that by adopting an inductive/interpretive approach to quantitative enquiry - following a path dictated by the emergence of data and structure, rather than looking to verify pre-determined ideas - we have surfaced a potentially useful and conceptually interesting arrangement that would not have emerged had we focused, at the outset, on building either a scale, or an index. And there is, anyhow, a current questioning of established and emerging empirical conventions in respect of both. Diamontopoulos, Riefler and Roth (2008), whilst largely championing a systematic approach to index development, also acknowledge opposing claims; and the efficacy of scales, too - along with their associated 'certainties', validity and reliability - are additionally being questioned (e.g. Bergkvist and Rossiter, 2007; Borsboom, Mellenbergh and van Heerden, 2004; Rossiter, 2002). It does not seem inappropriate, therefore, to further challenge the conventional wisdom, and an 'opportunistic' approach to the development of measures may well allow researchers to uncover and explore a wider range of measurement potential, at least at the developmental phase.

The research constituency on which we focused our investigations is relatively homogeneous. For the main part young ( $88 \% 35$ and under), and all exposed - through CIM academic programmes - to the current marketing orthodoxy. Average DMO score for the sample (3.58) implies, perhaps unsurprisingly, a rather more defensive than offensive orientation; Acknowledgement, Expedience and Idealism scores were all of a similar nature, at 3.49, 3.62 and 3.47 respectively. Our results, thus, have some explanatory merit in respect of a particular group of marketers, but we see more in the potential of the measure than we do in outputs based on the context of its development. We see, also, opportunities for improving the present structure/measure, but would encourage others, too, to initiate their own enquiries into the 
vagaries of 'the marketer mindset'. We suggest, therefore, an agenda for further research, with items of interest as follows:

a) Measurement focused on DMO, itself, is at an early stage of development. 'Opportunistic' activity has revealed one particular construct that represents key concept principles, but others will clearly exist. To assume there is but one 'correct' solution is to assume primacy/exclusivity of both method and interpretation when, clearly, neither is true. More work on concept representation would be of substantial value whilst, of course, further testing of the present structure will be necessary to further evaluate/improve its own validity and reliability.

b) There will doubtless be different opinions on how the 'marketer mindset' might best be characterised. As explained in earlier sections of this paper, DMO is a personally derived and directed perspective on marketing imperatives, and the nature of its development acknowledges Palmer and Ponsonby's (2002) view that both research endeavour and theory are largely socially constructed. There is, in reality, no 'best' way to pursue the broad agendas explored in this paper, and other, non-DMO, perspectives - focusing on which marketer/market characteristics might be of most empirical interest - would be equally valuable.

c) Given that marketing theory changes over time, it would be interesting to determine whether marketers, themselves, similarly evolve. Anecdotal evidence suggests marketers merely adapt, and then 'revert to type' as, and when, this suits. Is marketing practice, for example, determined more by the type of individual that is attracted to the mythology of marketing, and less by the theories to which they are exposed? Further research of both a longitudinal demographic nature would help clarify the relationships between marketing and the marketer. 
d) Are marketers, in particular cultures, different to their colleagues in other cultures? Extant theory is largely focused on ethics, but we know far less about - for example - how customer-centric 'full-time' marketers really are, or how they feel about their relationship with other organizational entities and/or agendas. Both nature and extent of 'marketer behaviour' research, generally, is surprisingly under-developed, and irrespective of which particular measure, or even mode of investigation (quantitative or qualitative) is utilised, we believe it important to be able to understand what drives and motivates the contemporary marketer. We are aware that the objectives of practising marketers (item 1, Figure 1) and those of marketing academe (item 4, Figure 1) are frequently mis-aligned, and without such understanding it is not possible to recommend effective solutions to perceived marketing problems.

\section{Conclusions}

Analysis of both the marketing and psychology literatures revealed that there is no existing instrument that evaluates attitudes of marketers in respect of MO or post-MO marketing concerns. Although many measures seek to determine the extent to which organisations, generally, are market, service and/or customer oriented, there is only very limited evidence of similar tests being applied to groups of marketers. Similarly, although specific categories of 'part-time marketer' (service workers and salespeople) have been the subject of orientation testing for more than twenty years, there appears to be an assumption that those who market strategically (and, coincidentally, full-time) are automatically imbued with market-oriented tendencies. There is, however, a small but substantive body of research that implies marketers are reactionary in nature, and that they prefer traditional/conventional models of marketing behaviour that appear, now, to be counter-productive in the context of 'new manifestos' and 
concerns recently occurring in the literature. Our results show that fledgling marketing managers veer slightly more toward the 'defensive' than 'offensive', though this may well be a function of educational conditioning rather than innate and enduring attitude.

The DMO construct is, as far as we can determine, the only one presently mooted that might usefully be employed to interrogate/identify the attitudes of practising marketers in respect of key, contemporary marketing issues. If applied both cross-sectionally and longitudinally the construct could prove useful in evaluating differences between marketer attitudes in different industries, cultures and countries, and for monitoring changes, over time, of marketer/strategy compatibility. The research reported herein was conducted primarily to explore the operational potential of Woodall's (2004) interpretation of defensive marketing. Exploratory factor analysis was used to facilitate a jointly deductive/inductive approach to data analysis, and proved both opportunistic and effective - though further work is required. It is evident though, even at this relatively early stage of development, that no marketer scoring 'well' on a DMO measure could be accused of being entirely "shallow, wasteful or polluting" (Sheth and Sisodia, 2005, p. 160); and a general trend towards higher scores over succeeding years may well imply that marketing is able to find its way out of the metaphorical doghouse - assuming, of course, that organisations regard this as a desirable trajectory. And this is by no means certain, for marketing - perhaps may always be the scapegoat that everyone loves to hate ... 


\section{References}

Abela, A. V. (2006). Marketing and consumerism: a response to O'Shaughnessy and O'Shaughnessy. European Journal of Marketing 40, 5-16.

Ardley, B. (2005). Marketing managers and their world; explorations in strategic planning using the phenomenological interview. Marketing Review 5, 111-127

Babin, B. J., Boles, J. S., and Robin, D. P. (2000). Representing the perceived ethical work climate among marketing employees. Journal of the Academy of Marketing Science 28, 345-358

Ball, D. (2004). The role of communication and trust in explaining customer loyalty. European Journal of Marketing 38, 1272-1293.

Bathgate, I., Omar, M., Nwankwo, S. and Zhang, Y. (2006). Transition to a market orientation in China; preliminary evidence. Marketing Intelligence and Planning 24, 332-346.

Bergkvist, L. and Rossiter, J. (2007). The predictive validity of multiple-item versus single-item measures of the same constructs. Journal of Marketing Research, 44, 175-184.

Berthon, P. and Pitt, L. (1998). The marketing amphisbaena: a comment on Gordon Foxall's 'The Marketing firm'. Journal of Strategic Marketing 6, 161-166.

Berry, L. L (1999). Discovering the Soul of Service: the Nine Drivers of Sustainable Success. New York: Free Press

Best, R. (2000). Market-based Management: Strategies for Growing Customer Value and Profitability ( $2^{\text {nd }}$ Ed.). Upper saddle River, N. J.: Prentice Hall

Black, L. D. and Härtel, C. E. J. (2002). Public relations orientation: development, empirical and implications for managers. Journal of Communication Management 7, 117-128.

Boles, J. S., Babin, B. J., Brashear, T. G., and Brooks, C. (2001). An examination of the relationships between retail work environments, salesperson selling orientation-customer orientation and job performance. Journal of Marketing Theory and Practice 9, 1-12.

Borsboom, D., Mellenbergh, G. J. and van Heerden, J. (2004). The concept of validity. Psychological Review, 111, 1061-1071.

Brady, J., and Davis, I. (1993). Marketing's mid-life crisis. The McKinsey Quarterly 2, 17-28.

Brady, M. K., and Cronin Jr., J. J. (2001). Customer orientation: effects on customer service perceptions and outcome behaviors. Journal of Service Research 3, 241-251.

Brady, M. and Palmer, R. (2004). What are they doing? A study of contemporary marketing practice in Ireland. Irish Journal of Management 25, 125-136. 
Brinkmann, J. (2002). Business and marketing ethics as professional ethics: concepts approaches and typologies. Journal of Business Ethics 41, 159-177.

Brown, S. (1995). Life begins at 40? Further thoughts on marketing's mid-life crisis. Marketing Intelligence and Planning 13, 4-17.

Brown, S. (1999). Retro-marketing: yesterday's tomorrows, today. Marketing Intelligence and Planning 17, 363-376.

Brown, S. (2005). Marketing has reached its tripping point. Marketing News 39, 28-32.

Brown, S. W. (2005). When executives speak, we should listen and act differently. (pp.1-4) In Marketing Renaissance: Opportunities and Imperatives for Improving Marketing Thought, Practice, and Infrastructure. Edited by Bolton, R. Journal of Marketing 69, 1-4.

Brown, T. J., Mowen, J. C., Donavan, D. T. and Licata, J. W. (2002). The customer orientation of service workers: personality trait effects on self- and supervisor-performance ratings. Journal of Marketing Research 39, 110-119.

Camacho. L. M. and Paulus, B. (1995). The role of anxiousness in group brainstorming. Journal of Personality and Psychology 68, 1071-1082.

Carraher, S. M., Mendoza, J. L., Buckley, M. R., Schoenfeldt, L. F., and Carraher, C. E. (1998). Validation of an instrument to measure service-orientation. Journal of Quality Management $\mathbf{3}$, 211-224.

Carrigan, M., Marinova, S. and Szmigin, I. (2005). Ethics and international marketing: research background and challenges. International Marketing Review 22, 481-493.

Carù, A. and Cova, B. (2003). Revisiting consumption experience: a more humble but complete view of the concept. Marketing Theory 3, 267-286.

Chatzipanagiotou, K. C., Vassilikopoulou, A. and Siomkos, G. J. (2008). An empirical investigation of the relationship between market orientation and MrkIS effectiveness in upscale hotels in Greece. Journal of Targeting, Measurement \& Analysis for Marketing 16, 285-297

Churchill, G. A., Jr. (1979). A paradigm for developing better measures of marketing constructs. Journal of Marketing Research 16, 64-73.

Clark, B. H. (2000). Managerial perceptions of marketing performance: efficiency, adaptability, effectiveness and satisfaction. Journal of Strategic Marketing 8, 3-25.

Coltman, T. (2008). Formative versus reflective measurement models: two applications of formative measurement. Journal of Business Research 61, (12), 1250-1262

Cova, B. (2005). "Thinking of marketing in meridian terms", Marketing Theory 5, 205-214. 
Coviello, N. E., Brodie, R., Danaher, P. J. and Johnston, W. J. (2002). How firms relate to their markets: an empirical examination of contemporary marketing practices, Journal of Marketing 66, 33-46.

Cran, D. J. (1994). Towards validation of the service orientation construct. Service Industries Journal 14, 34-44.

Dailey, R. M. and Kim, J. S. (2001). To what extent are 'Principles of Marketing' students market oriented? The review category: market education. Marketing Education Review 11, 5772.

Davidson, J. H. (1972). Offensive Marketing: or How to Make Your Competitors Follow. London: Cassell.

Davidson, J. H. (1997). Even More Offensive Marketing. London: Penguin.

De Chernatony, L., Drury, S., and Segal-Horn, S. (2003). Building a services brand: stages, people and orientations. The Service Industries Journal 23, 1-21.

Deepak, S., Singh, J., and Sabol, B. (2002), Consumer trust, value and loyalty in relational exchanges. Journal of Marketing 66, 15-37.

Deshpande, R. (1999). What are the contributions of marketing to organisational performance and societal welfare? Journal of Marketing 63, 164-167.

Deshpandé, R., Farley, J. U., and Webster Jr., F. E. (1993). Corporate culture, customer orientation, and innovativeness in Japanese firms: a quadrad analysis. Journal of Marketing 57, 23-27.

DeVellis, R. F. (2003). Scale Development: Theory and Applications. Thousand Oaks, California: Sage.

Diamantopoulos, A. and Siguaw, J. A. (2006). Formative versus reflective indicators in organisational measure development: a comparison and empirical illustration. British Journal of Management 17 (4), 263-282.

Diamantopoulos, A. and Winklhofer, H. (2001). Index construction with formative indicators: an alternative to scale development, Journal of Marketing Research, 38, 269-277.

Dobscha, S. (1998). The lived experience of consumer rebellion against marketing. Advances in Consumer Research 25, 91-97.

Donavan, D. T., Brown, T. J., and Mowen, J. C. (2004). Internal benefits of service-worker customer orientation: job satisfaction, commitment, and organisational citizenship behaviours. Journal of Marketing 68, 128-146. 
Dwairi, M., Bhuian, S. N. and Jurkus, A. (2007). Revisiting the pioneering market orientation model in an emerging economy. European Journal of Marketing 41, 713-721

Egan, C., and Shipley, D. (1995). Dimensions of customer orientation: an empirical investigation of the UK financial services sector. Journal of Marketing Management 11, 807-906.

Ellis, P. D. (2006). Market orientation and performance: a meta-analysis and cross national comparisons. Journal of Management Studies 43, 1089-1107.

Foley, A. and Fahy, J. (2004). Towards an understanding of the development of market orientation in the firm: a conceptual framework based on the market-sensing capability. Journal of Strategic Marketing 12, 219-230.

Fornell, C. and Wernerfelt, B. (1987). Defensive marketing strategy by customer complaint management. Journal of Marketing Research 24, 337-346

Foster, J. J. (1998). Data Analysis Using SPSS for Windows. London: sage

Franke, G. R. and Park, J-E. (2006). Salesperson adaptive selling behaviour and customer orientation. Journal of Marketing Research 43, 693-702.

Frei, R. L. and McDaniel, M. A. (1998). Validity of customer service measures in personnel selection: a review of criterion and construct evidence. Human Performance 11, 1-27.

Fromm. E. (1949). Man for Himself: an Enquiry into the Psychology of Ethics. London: Routledge and Keegan Paul.

Fuan, L., Zhou, N., Kashyap, R. and Yang, Z. (2008). Brand trust as a second-order factor. International Journal of Market Research 50, 817-839.

Grönroos, C. (2006). “On defining marketing: finding a new roadmap for marketing”. Marketing Theory, 6, 395-417

Grönroos, C. (2007). In Search of a New logic for Marketing, Chichester: John Wiley and Sons

Gummesson, E. (1991). Marketing-orientation revisited: the crucial role of the part-time marketer. European Journal of Marketing 25, 60-75.

Hajjat, M. M. (2002). Customer orientation: construction and validation of the CUSTOR scale. Marketing Intelligence and Planning 20, 428-441.

Halliday, S. V. (2002). Barriers to customer-orientation: a case applied and explained. European Journal of Marketing 36, 136-158.

Harris, E. G., Mowen, J. C. and Brown, T. J. (2005). Re-examining salesperson goal orientations: personal influencers, customer orientation and work satisfaction. Journal of the Academy of Marketing Science 33, 19-35. 
Hauser, J. R. and Shogun, S. M. (1983). Defensive marketing strategies. Marketing Science 2, 319-360.

Helm, S. (2005). Designing a formative measure for corporate reputation. Corporate Reputation Review 8, (2), 95-109

Hinkin, T. R. (1995). A review of scale development in the study of behaviour in organisations. Journal of Management 21, 967-988.

Hinkin, T. R. (1998). A brief tutorial on the development of measures for use in survey questionnaires. Organisational Research Methods 1, 104-121.

Hogan, J., Hogan, R., and Busch, C. M. (1984). How to measure service orientation. Journal of Applied Psychology 69, 167-173.

Holbrook, M. B., and Hulbert, J. M. (2002). Elegy on the death of marketing: never send to know why we have come to bury marketing but ask what you can do for your country churchyard. European Journal of Marketing 36, 706-732.

Homburg, C., Hoyer, W. D., and Fassnacht, M. (2002). Service orientation of a retailer's business strategy: dimensions, antecedents, and performance outcomes. Journal of Marketing 66, 86-101.

Jarvis, C. B., McKenzie, S. B. and Podsakoff, P. M. (2003). A critical review of construct indicators and measurement model misspecification in marketing and consumer research. Journal of Consumer Research, 30, 199-218.

Keegan, W., Davidson, J. H. and Brill, A. B. (2005). Offensive Marketing: an Action Guide to Gaining the Offensive in Business. Amsterdam; Boston: Butterworth-Heinemann

Kelley, S. W. (1992). Developing customer orientation among service employees. Journal of the Academy of Marketing Science 20, 27-36.

Kirca, A. H., Jayachandran, S., and Bearden, W. O. (2005). Market orientation: a meta-analytic review and assessment of its antecedents and impact on performance. Journal of Marketing 69, 24-41

Kline, P. (1998). The New Psychometrics: Science, Psychology and Measurement. London: Routledge

Kohli, A. K., and Jaworski, B. J. (1990). Market orientation: the construct, research propositions, and managerial implications. Journal of Marketing 54, 1-18.

Kohli, A. K., Jaworski, B. J., and Kumar, A. (1993). MARKOR: a measure of market orientation. Journal of Marketing Research 30, 467-477. 
Kolar, T. (2006). Benchmarking market orientation of banks in transitional markets: Exploring a modified approach. International Journal of Bank Marketing 24, 76-97

Kumar, K. R. and Sudharshan, D. (1988). Defensive marketing strategies: an equilibrium analysis based on decoupled response function models. Marketing Science 34, 805-816.

Lado, N., Maydeau-Olivares, A. and Rivera, J. (1998). Measuring market orientation in several populations: a structural equations model. European Journal of Marketing 32, 23-39.

Liao, M-N., Foreman, S., and Sargeant, A. (2001). Market versus societal orientation in the nonprofit context. International Journal of Nonprofit and Voluntary Sector Marketing 6, 254268.

Lin, C-H, Sher, P. J. And Shih, H-Y (2005). Past progress and future directions in conceptualising customer perceived value. International Journal of Service Industry Management, 16, 318-336.

Liu, C-M. and Chen, K-J. (2006). Personality traits as antecedents of employee customer orientation. International Journal of Marketing Management 23, 478-485.

Luo, X. and Seyedian, M. (2003-4). Contextual marketing and customer-orientation strategy for e-commerce: an empirical analysis. International Journal of Electronic Commerce 8, 95-118.

Lusch, R. F. and Vargo, R. L., 2006. Service-dominant logic: reactions, reflections and refinements. Marketing Theory 6, 281-288.

Lynn, M. L., Lytle, R. S. and Bobek, S. (2000). Service orientation in transitional markets: does it matter? European Journal of Marketing 34, 279-298.

Lytle, R. S., Hom, P. W., and Mokwa, M. P. (1998). SERV*OR: a managerial measure of organisational service-orientation. Journal of Retailing 74, 445-489.

Lytle, R. S. and Timmerman, J. E. (2006). Service operation and performance: an organizational perspective. Journal of Services Marketing 20, 136-137.

Macedo, I. M. and Pinho, J. C. (2006). The relationship between resource dependence and market orientation: The specific case of non-profit organizations. European Journal of Marketing 40, 533-553.

Maltz, E. and Kohli, A. K. (2000). Reducing marketing's conflict with other functions: the differential effects of integrating mechanisms. Journal of the Academy of Marketing Science 28, 479-492.

Mattsson, J., Ramaseshan, R. and Carson, D. (2006). Let marketers reclaim corporate strategy. Journal of Strategic Marketing 13, 61-77. 
Michaels, R. E., and Day, R. L. (1985). Measuring customer orientation of salespeople: a replication with industrial buyers. Journal of Marketing Research 22, 443-446.

Mitchell, I. S., and Agenmonmen, A. I. (1984). Marketers' attitudes toward the marketing concept in Nigerian Business and non-business operations. Columbia Journal of World Business 19, 62-71.

Mohr-Jackson, I. (1998). Conceptualising total quality orientation. European Journal of Marketing 32, 13-22.

Moorman, C. (1998). Cynical consumers: scepticism and faith in the marketplace. Advances in Consumer Research 25, 215.

Nairn, A. and Berthon, P. (2003). Creating the customer: the influence of advertising on consumer market segments. Journal of Business Ethics 42, 83-100.

Narver, J. C, and Slater, S. F. (1990). The effect of a market orientation on business profitability. Journal of Marketing 54, 20-35.

Neiderman, R. (1999). The conceptualization of a Model of Spirituality. Unpublished doctoral dissertation, University of Georgia, Athens. Retrieved 24/06/07, from www.geocities.com/randynied/home.html

O’Donohoe, S. (2001). Living with ambivalence: attitudes to advertisements in postmodern times. Marketing Theory 1, 91-108.

Oppenheim, A. N. (1992). Questionnaire Design, Interviewing, and Attitude Measurement. $\left(2^{\text {nd }}\right.$ Ed). London: New York: Continuum.

Palmer, A. and Ponsonby, S. (2002). The social construction of new marketing paradigms: the influence of personal perspective. Journal of Marketing Management 18, 173-192.

Peterson, R. A. (1994). A meta-analysis of Cronbach's coefficient alpha (measure of scale reliability). Journal of Consumer Research 21, 381-391.

Plotnick, E (1997). Concept mapping: a graphical system for understanding the relationship between concepts. Retrieved 27/8/04, from http://www.ericfacility.net/ericdigests/ed407938.html

Pole, C., and Lampard, R. (2002). Practical Social Investigation: Qualitative and Quantitative Methods in Social Research. Harlow: Prentice Hall.

Rindfleisch, A., and Moorman, C. (2003). Interfirm co-operation and customer orientation. Journal of Marketing Research 40, 421-436.

Rorty, R. (1989). Contingency, Irony, and Solidarity, New York: Cambridge University Press. 
Rossiter, J. R. (2002). The C-OAR-SE procedure for scale development in marketing. International Journal of Research in Marketing 19, (4), 305-335.

Rudd, J. M. and Morgan, R. (2003). Editorial - marketing strategy: a history of the next decade. Journal of Strategic Marketing 11, 161-164.

Ruiz, D. M., Washburn, J. H. and Carrion, G. C. (2008). Service value revisited: specifying a higher-order, formative measure. Journal of Business Research, 61, 1278-1291

Rust, R. T. (2006). From the editor: the maturation of marketing as an academic discipline. Journal of Marketing 70, 1-2.

Rust, R. T. And Moorman, C. (1999). The role of marketing. Journal of Marketing 63, 180-197.

Rust, R. T., Zahorik, A. J. and Keiningham, T. L. (1996). Service Marketing, New York: HarperCollins

Sanchez, A. O. and Fuentes, M. T. M. (2002). Consumer orientation of public hospital websites in Spain. International Journal of Medical Marketing 3, 20-30.

Sanzo, M. J., Santos, M. L., Vázquez, R., and Ălvarez, L. I. (2003). The role of market orientation in business dyadic relationships: testing and integrator model. Journal of Marketing Management 19, 73-107.

Saura, I. G., Contrí, G. B., Taulet, A. C. and Velázquez, B. Z. (2005). Relationships among customer orientation, service orientation and job satisfaction in financial services. International Journal of Service Industry Management 16, 497-525.

Saxe, R., and Weitz, B. A. (1982). The SOCO scale: a measure of the customer orientation of salespeople. Journal of Marketing Research 19, 343-351.

Schneider, B., White, S. S., and Paul, M. C. (1995). Linking service climate and customer perceptions of service quality: test of a causal model. Journal of Applied Psychology 83, 150163.

Schriesheim, C. A., Powers, K. J., Scandura, T. A., Gardiner, C. C., and Lankau, M. J. (1993). Improving construct measurement in management research: comments and a quantitative approach for assessing the theoretical content adequacy of paper-and-pencil survey-type instruments. Journal of Management 19, 385-417.

Sheth, J. N. (2005). A dangerous divergence: marketing and society. Journal of Public Policy \& Marketing 24, 160 - 162

Sheth, J. N and Sisodia, R. S. (2005) Does marketing need reform? In Marketing Renaissance: Opportunities and Imperatives for Improving Marketing Thought, Practice, and Infrastructure. Edited by Bolton, R. Journal of Marketing 69, 10-12. 
Siguaw, J. A., Brown, G., and Widing II, R. E. (1994). The influence of the market orientation of the firm on sales force behaviour and attitudes. Journal of Marketing Research 31, 106-116.

Singhapakdi, A., Vitell, S. J., Rao, C. P. and Kurtz, D. L. (1999). Ethics gap: comparing marketers with consumers on important determinants of ethical decision making. Journal of Business Ethics 21, 317-328.

Srivastava, R. K., Tassaduq, A. S., and Fahey, L. (1999). Marketing, business processes, and shareholder value: an organisationally embedded view of marketing activities and the discipline of marketing. Journal of Marketing 63, 168-179

Susskind, A. M., Kacmar, K. M., and Borchgrevink, C. P. (2003). Customer service providers' attitudes relating to customer service and customer satisfaction in the customer-server exchange. Journal of Applied Psychology 88, 179-187.

Tadepalli, R. (1995). Measuring customer orientation of a salesperson: modifications of the SOCO scale. Psychology and Marketing 12, 177-187.

Tan, S. J. (2004). Can consumer's scepticism be mitigated by claim objectivity and claim extremity? Journal of Marketing Communications 8, 45-64.

Teas, R. K., and Palan, K. M. (1997). The realms of scientific meaning framework for constructing theoretically meaningful nominal definitions of marketing concepts. Journal of Marketing 61, 52-67.

Thomas, R. W., Soutar, G. N., and Ryan, M. M. (2001). The selling orientation-customer orientation (S.O.C.O.) scale: a proposed short form. Journal of Personal Selling and Sales Management 21, 63-69.

Vargo, S. L., and Lusch, R. F. (2004). Evolving to a new dominant logic for marketing. Journal of Marketing 68, 1-16.

Wang, J. and Wallendorf, M. (2006). Materialism, status signaling and product satisfaction. Journal of the Academy of Marketing Science 34, 494-505

Webster, C. (1993). Refinement of the marketing culture scale and the relationship between marketing culture and profitability of a service firm. Journal of Business Research 26, 111-131.

Webster Jr., F. E. (2005). Back to the future: integrating marketing as tactics, strategy and organizational culture. In Marketing Renaissance: Opportunities and Imperatives for Improving Marketing Thought, Practice, and Infrastructure. Edited by Bolton, R. Journal of Marketing 69, 4-6

Weinzimmer, L. G., Bond III, E., Houston, M. B and Nystrom, P. C. (2003). Relating marketing expertise on the top management team and strategic market aggressiveness to financial performance and shareholder value. Journal of Strategic Marketing 11, 133-159. 
Wilson, M., and McDonald, M. (1994). Marketing at the crossroads - a comment. Marketing Intelligence and Planning 12, 42-45.

Winch, G. and Joyce, P. (2006). Exploring the dynamics of building, and losing, consumer trust in B2C e-business. International Journal of Retail and Distribution Management 34, 541-555.

Wright, N. D., Pearce, J. W., and Busbin, J. W. (1997). Linking customer service orientation to competitive performance: does the marketing concept really work? Journal of Marketing Theory and Practice 5, 23-34.

Woodall, 2004. Why marketers don't market: reconceptualising 'offensive' and 'defensive' archetypes. Journal of Marketing Management 20, 559-576.

Wycoff, J. (1991). Mindmapping: your personal guide to exploring creativity and problemsaving. New York: Berkley Books

Zeithaml, V. A., Parasuraman, A., and Malhotra, A. (2002). Service quality delivery through web sites: a critical review of extant knowledge. Journal of the Academy of Marketing Science 30, 362-375. 